ture (noticed in four other cases of intracranial abscess from injury), as evidence of a local and not diffuse inflammation within the skull, is here well exemplified.

On October 21st, 1881, an Irish day labourer, aged sixty vears, was admitted into Broderipp ward suffering from the effects of an injury to his head received fourteen days previonsly. He complained of severe pain darting through his head from a slightly ecchymosed lump in the right temple distant the breadth of two fingers from the external angular process of the frontal bone and just below the temporal ridge. Pressure upon this spot aggravated the pain. His face had a heavy expression, and he spoke in a slow deliberate manner, but his mind was perfectly clear; he gave a consistent account of the accident, mentioning dates and correcting his wife's narrative when he thought her statements inaccurate. His pulse beat only 56 per minute, and it was very compressible. His temperature was normal. His tongue was dry, and brown along the middle. $\mathrm{He}$ walked feebly into the ward, but did not require any support, and no motor palsy or loss of surface sensibulity was present. He related that fourteen days previously whilst kneeling on the ground and stooping his head down to look into a drain (he had on a stout felt hat) a falling ladder, twenty-five feet long, struck him a glancing blow on the right temple, which threw him down and stunned him for a few moments. He soon recovered, rose, and went on with his work, at which he continued during the remainder of that day, the whole of the following, and part of the third day after the accident. Throughout this time he had great headache, and on the third day this was so severe as to oblige him to desist from working and go home. Since that time he had not left his room till he was brought to the hospital. The severity of the headache was such that at times his wife feared "he would go out of his mind,' and during the intensest paroxysms it was accompanied with so much giddiness that he could only walk by steadying himself by grasping a chair. His wife said that on the evening of the accident when he come home from work she saw that he had a large bruised lump on his right temple, and that two days later the evelids of both sides, but especially of the right eye, were black, but the "white of the eyes" was not black. The symptoms during the next two days after his reception into the hospital did not materially change. On the second day (0ct. 22nd) his pulse was 60 per minute and his temperature $97^{\circ} \mathrm{F}$. On the third day the pulse was 60 , the temperature $98^{\circ} \mathrm{F}$, and he had a restless night, muttering incoherently. On the fourth day he muttcred much, was quite incoherent, tried to leave his bed, asked for his clothes, wanted to go home; but when spoken to he understood perfectly what was said to him, and he replied pertinently. On the fifth day he was lethargic, but he took food when it was offered to him, and he answered pertinently when addressed. On the following day retention of urine supervened, requiring the use of the catheter, which he resented, pushing down his shirt when it was raised. $\mathrm{He}$ lay on his back, with his left hand on the vertex of his head, and he sometimes spontaneously drew up his left foot and planted it on the mattress, keeping the knee bent. When pinched he drew the foot up sharply. His right arm lay relaxed by his side, and he was evidently unable to move it, and the right leg was similarly palsied. A nip excited scarcely any reflex movement of the right arm and leg. The question of trephining was considered, but his wife obstinately refused to permit any operation. On the seventh day there was increased lethargy. Even when loudly spoken to he took no notice. Temperature $98.6^{\circ} \mathrm{F}$. and pulse 70. On the eighth day the torpor appeared deeper; he was feebler; he still swallowed fluid nourishments when put into his mouth. On the ninth day, between the times of using the catheter, he micturated into his bed; this continued through the following day. In other respects his condition was not obviously changed. On the eleventh day (Nov. 1st) towards the afternoon a spastic rigidity of the left arm was first observed, which resisted extension. 'This arm was occasionally twitched.

At 7 P.M. on Nov. 1st, his wife having yielded, the scalp was reflected at the bruise in the right temple, and the pericranium was turned back off a sufficient space to permit the application of a small trephine. The outer surface of the bone did not exhibit any morbid appearance. A disc $8 \mathrm{~mm}$, in diameter having been cut out, the diploë and the inner table appeared to be normal. A small meningeal artery, which, as it grooved the bone, had been necessarily severed, spirted freely, but the bleeding was soon checked by pressure. The exposed dura mater appeared to be healthy, but it bulged up so tensely into the bore-hole that cerebral pulsation could neither be seen nor felt. An aspiration-needle connected with a partially exhausted syringe was next pushed through the dura mater, and when the point of the needle had entered to the depth of an incb, quantity of brown flocculent fluid flowed into the receiver. As the fluid continued to flow through the prick-hole in th: membrane after the needle was withdrawn, this hole was enlarged with a narrow scalpel passed to about the same depth as the needle, which permitted a further escape of fluid. The total quantity of fluid thus evacuated was estimated at from three to four drachms. The scalp. flaps were replaced, their edges united with a fine suture, and a slip of oiled silk inserted into the middle of the wound for a drain. The entire wound was covered with a bunch of boric-lint charpie, kept in place by a linen skullcap. The operation was performed under chloroform. No vomiting followed. One hour later the man seemed less unconscious; he indicated his want of food, and took it readily when given him, which he had not done for several days.

Next morning, the twelfth day from the date of his admission into the hospital, the patient recognised those around him, and replied pertinenlly when addressed. He asked for a pipe and smoked; when this was given to him, holding it with his left hand, the spastic rigidity of the left arm had disappeared. Temperature $98^{\circ} \mathrm{F}$, , and pulse 67. The charpie being soaked with the same kind of turbid brown fluid which had escaped from the incision through the dura mater, was renewed.

On the following day (Nov. 3rd) a very marked improvement in his condition was evident. He himself said he felt better. The palsy of the right arm was disappearing; he could raise it off the bed and bring the hand nearly to his mouth. Temperature $974^{\circ}$; pulse 74 .

Next day (Nov. 4th), the fourth day after trephining, the patient felt so much better that he wished to get up. Temperature $97^{\circ} \mathrm{F}$. ; pulse 80 . - 7th : He could move his right arm and hand evenly and freely. -8 th : He spent the morning in reading the Irish Nation newspaper. The sutures were removed, a slight redness having appeared around them. Temperature $97^{\circ}$; pulse $80 .-11$ th : He had a restless uight, and this morning he complained of headache. Temperature $100^{\circ}$; pulse 100 , hard ; tongue furred. It was elicited that, contrary to a strict injunction that he should not leave his bed, he had taken advantage of the temporary absence of the nurse, and had got up and gone to the watercloset. A purge was given which acted freely, and after this the headache abated, and the temperature and pulserate declined. From this date his recovery was uninterrupted.

By Dec. 1st, one month after the operation, the patient was considered convalescent, but for precaution he was detained in hospital until Jau. 2nd, when he went home, feeling quite well, and with the intention of returning to work.

\section{SUSSEX COUNTY HOSPITAL.}

SEQUET TO A CASE OF EXCISION OF THE RECTUM FOR EPITHELIAL CANCER.

(Under the care of Mr. WILloughBY TURNER, F.R.C.S.)

THIS case was reported in THE LANCET on March 15th, 1879. An epitome of that report is as follows:-

Mary M-, aged sixty-four, was admitted for an epithelial cancer (cylindrical epithelioma) of the rectum. She had had pain and bleeding for two years before admission. The growth occupied the left side of the rectum, and its highest limit was two inches and a half above the anus. It extended more in front than posteriorly. A portion of the rectum was excised, chiefly with the knife; but the benzoline cautery was used to divide the bowel. The result was good; she could hold her motions, and there was entire relief from pain and hæmorrhage. On October 20th, 1880, two years and a half after the operation, the patient was readmitted with a recurrence of the growth in the recto-vaginal septum. This was removed by the knife. It extended so high that to ensure its entire removal the peritoneum was exposed and separated from the front wall of the rectum for a distance of rather more than half an inch. The result was again good; and when she left the hospital she was in comfort and had control over her motions. On June 6tb, 1883, the patient was again admitted complaining of pain in the region of the 
anus, especially on getting about. There was found to be an extensive recurrence, which occupied the tissues in the ischio-rectal fossa on both sides. This was again removed by the knife. So high had the dissection to be carried on either side of the buwe. that the apex of the ischio-rectal fose $\rightsquigarrow$, where the obturator internus and levator ani meet, was reached. The hæmorrhage was copious, and very many vessels were ligatured. About half an inch of the gut was invaded, and was also taken away. The operation was borne well, and it was surprising how quickly the granulatiog process progressed. To expedire matters, a deep suture was introduced after the granulations bad spruog up, and this served well to bring the parts more in contact. Fur some time after the operation mutions passed involuntarily into the wound. Eight weeks after the operation she was discharged in very good health and with increasing power in the rectum. On September $19 ! \mathrm{h}, 1883$, she walked to the hospital and stated that she again had control over her motions and was quite free from pain.

Remarks by Mr. TuRNER. - The cancer bas now a history of about seven years' growth, and in all probability would have proved fatal long ago had it not been removed. At each operation the tissues were divided wide of the disease ; nevertheless, at intervals of about two years and a half on each occasion, there was a recurrence, not in the cicatrix of the previous operation, but in the adjacent tissues. A marked feature of the growth was the accompanying pain, constant and of a so-called dull boring character, not caused or increased by the passage of fæces over the surface, for this in the last two recurrences was not ulcerated. Colutomy therefore would have failed to relieve. The microscopical characters were those of cylindroma. No secondary growth could be felt in the liver or elsewere.

\section{altedical Sorcitics.}

\section{PATHOLOGICAL SOCIETY OF LONDON.}

Diverticula in the Intestines.-Obliteration of Coronary Artery.-Congenital Club-foot.-Rupture of the Heart.Structure of Internal Homorrhoids. -Necrosis of the Lower Jaw.

THE ordinary meeting of this Society took place on Tuesday, Nov. 6th, the President, Mr. J. Whitaker Hulke, F.R.S., in the chair. Several communications of interest were read; and foremost amongst the speakers was Dr. Wilks, a former president, who has not ceased to take an active interest in the proceedings of this Society.

Dr. NORMAN MOORE exhibited the Intestines of a man aged forty, showing three Diverticula in the first three feet of the small intestine, and a Congenital Stricture at the com. mencement of the Jejunum. The diverticala were each an inch long and about as much in diameter, and were on the mesenteri, side of the intestine. Their walls consisted of all the intestinal coats, and they were not mere hernid protrusions; they inight, perhaps, have some relation to the pyloric cæca of Pirces. The stricture was caused by an internal ring of mucous nembrane, and would just admit the little finger. Ic was ohviuusly a variatinn in development, and not due to any morbid change. Nrither peculiarity gave rise to symptums, and the man died of bronchitis. Such cæca have been described, but were very rare, while a congeuital stricture so high up in the small intestine was still rarer.-Mr. Frederick Treves had seen a large number of intestinal diverticula, not only near the mesenteric border, but also high up in the intestine. It was difficult to prove that such cases were not connected in any way with obstruction.Mr. SUTTON mentioned a case which had come under his observation at the Middlesex Hospital. Here there was a curious malformation, for there was complete obstruction of the duodenum, the intestine ending in a cul-de-sac. The specimen was found in a child, who had survived its birth four or five days, and had been fed on milk and brandy. Complete strictures of the bowel here were very rare, but constrictions were common.-Dr. GOODHART said that it was not clear that Dr. Moore's case might not have been due to dis. tension, which had long pussed by. A specimen existed in the museam of the College of Suryeons of somewhat similar characters. - Dr. MOORE, in reply, said that there was no history of intestinal obstruction in his case. With regard to the rarity, what be meant to say was tbat they wele rare, though not neces: arily unique. Out of 3400 examinations at St. B.rtbolomew's Huspital, only this case occurred, whilst there were twenty-seven cases of Meckel's diverticula.

Dr. SAMUEL WEST showed a specimen of a Heart taken from a man aged fifty who had "cardiac dropsy" during life. The heart was dilated, large, heavy, and fatty. The aortic valves were thickened, but not iucompetent. The most re. markable $f \in a t u r e$ was the atheromatous coudition of the aoria. The right coronary artery was slightly narrowed at its opening into the aorta; but the o.itice of the left coronary artery could not be found, and was clused by a calcareous plate; the vessel, however, contained blood right up to its obstructed point. Cases of obstruction of the coronary arteries are by no means common, but several have been recorded in the Pathological Transactions, and notably twelve cases by Dr, Ogle. They were mostly con. nected with atheroma of the vesefle, and generally with old clots in their iuterior. In one case the artery was reduced to a fibruus cord. In another case of a male who died of cancer, no cardiac symptoms had existed, and yet both corunary arteries were obstructed. Instancts of partial ob. structiou are common, but not so instances of complete oblitt:ration of the calibre. The question of the blood-supply of the heart was then entesed into. Dr. West had found that there was a free anastomosis between the coronary arteries of both sides. (Vide THE LANCET, vol. i., 1883, p. 945.) What was the source of the bluod-supply in cases of obstruction? Authors bad referred to arteriæ adiposæ, which $m a y$ arise indepeudeutly from the aorta. In some of the lower animals no co onary arteries existed, and there it seemed that branches arose separately from the ventricle. In these cases of coronary obstruction the pulse was not markedly slow as a rule. We must suppose, then, that the blood speed was greater, and this might be brought about by increased action of the heart or increased tension in the aorta. Some have thought there came into play a sort of suction during diastole, but this was opposed to the observations of Martin and Sedgwick, which showed that curonary tension agreed with the blood pressure in the large arteries of the body. We must fall back on the notion that there existed some kind of collateral circulation.-Mr. HENRY MORRIS said that some few years ago he called in question the statement of Hyrtl. Fom trials with the hearts of very young subjects Mr. Karop had in no instance failed to inject one artery from the other.-Mr. SHATTOCK said that Hyrtl's results could be explained because he used wax, and this probably corroded his specimens. If a fine injection be used, it could be shown that the lingual arteries anastomosed freely, which fact had been denied by some.Mr. HULKE said that similar mistakes had been made with regard to the hear of the femur as well as to the tongue. But in the heart the question had more than an anatonical bearing.-Dr. WEST supplemented his paper by sdyung that in a part of the heart that should not bave been iujecred, accord. ing to Hyrtl, it was found on microscopical examination that the capillaries were beautifully filled with coloured fluid.

Mr. R. W. PARKER exhıbited, with Mr. SHatTock, some specimens of Congenital Club-foot. In one fout the muscles and nerves were dissected; in the other fuot the shape of the tarsal bones was demonstrated. The authors likewise showed microscopi: preparations of the spiual cord and nerve trunks and of each of the muscles of the limb. These exhibited no apureciable devi $x$ tion from the normal histological structure. In the bones, however, certain changes were described, but the authors considered that these alterations were not primary, but were the result of the altered yosition in which the bones bad lain. They based this view chiefly on the fact that, though altered in extent, the normal outlines of the articular surfaces could still be distinctly traced. Reviewing the various theories of causation, they rejected the neural theory on the evidence of their own case; for a like reason, the bone theory, which the late Prof. Hueter had chiefly supported, was dismissed, and they agreed with Mr. Wr. Adams that these changes were a result, aud not a cause. As to whether the talipes is only an exaggeration of a normal standard they felt undecided, because some additional pnwer is required to bring about a well-marked case. They believed that the mechanical theory in some shape or other best explained their own case. Brief allusion was also made to the insufficiency of the classitication into the convenital and non-congenital forms. The authors think nerve lr sions may exist in some congenital cases. - Irr. ADdMs was pleased with the specimens exhibited, be. 